\title{
Influence of InGaN waveguide on injection efficiency in III-nitride laser diodes
}

\author{
MATEusz HAJDEL*, GrZEgorZ MUZIOŁ, KRZESIMIR NOWAKOWSKI-SZKUDLAREK, \\ Marcin SIEKACZ, PawEŁ WOLNY, CZEStaw SKIERBISZEWSKI \\ Institute of High Pressure Physics "Unipress", PAS, \\ Sokołowska 29/37, 01-142 Warsaw, Poland \\ ${ }^{*}$ Corresponding author: hajdel@unipress.waw.pl
}

\begin{abstract}
The influence of using InGaN waveguides on blue laser diodes was theoretically studied using 1D drift diffusion model and 2D optical mode calculation. Despite of the known effect of increased confinement of an optical mode, especially for long wavelengths, an unexpected influence on the efficiency of carrier injection into the active region is discussed. It is found that InGaN-AlGaN interface is crucial to achieving high injection efficiency. A numerical model is created, which describes the influence of InGaN waveguide and $\mathrm{Mg}$ doping of electron blocking layer on basic properties of laser diodes. It is found that an increase of injection efficiency allows to reduce the doping level in an electron blocking layer and take advantage of decreased optical losses.
\end{abstract}

Keywords: InGaN, laser diodes, waveguide, injection efficiency.

\section{Introduction}

The III-nitride laser diodes (LDs) are promising candidates to being reliable, cheap, and efficient light sources for variety of applications such as general lighting, laser projectors and data storage systems [1]. In the majority of violet InGaN LDs the GaN waveguides (WGs) are used [2]. However, in long wavelength devices, the optical mode is less confined with the active region [ $\underline{3}-\underline{6}]$. The refractive index contrast between $\mathrm{GaN}$ waveguide and $\mathrm{AlGaN}$ claddings drops, which causes the decrease of optical confinement factor $\Gamma$ [ [5]. Theoretical and experimental studies have shown that replacing GaN with InGaN WGs can increase the confinement of the optical mode with the active region, especially for lasers emitting longer wavelengths $(>450 \mathrm{~nm})$ [7-9]. Additionally, InGaN WGs can be successfully used to ensure a good quality laser beam by preventing mode leakage to the substrate $[\underline{10}]$.

The main bottleneck which prevented the commercialization of III-nitride LDs was high optical losses caused in majority by Mg-doped layers [1-13]. This problem has 
been solved by inserting an undoped layer between quantum wells and Mg-doped layers, which decreased the overlap of the optical field with these layers. Introducing the InGaN WGs also changes the confinement in Mg-doped layers and can reorder their contribution to overall optical losses $\alpha_{\mathrm{i}}$. Special attention should be given to the electron blocking layer (EBL) since it is the highest p-type doped layer placed right after the active region to prevent carrier overflow and ensure high carrier injection efficiency $\eta_{\mathrm{i}}$ into quantum wells. High Mg doping in EBL is necessary to ensure high $\eta_{\mathrm{i}}$. Low $\alpha_{\mathrm{i}}$ and high $\eta_{\mathrm{i}}$ are crucial to obtain high efficiency LD with low threshold current.

In this work we show via theoretical simulations that the InGaN WGs not only increase $\Gamma$ and decrease losses originating from $\mathrm{Mg}$ doped layers but also increase $\eta_{\mathrm{i}}$. This can be used to further improve the performance of III-nitride LDs by a decrease of the Mg-doping level in EBL and thus obtain a reduction of $\alpha_{\mathrm{i}}$.

\section{Simulation framework}

To study band diagrams and $\eta_{\mathrm{i}}$ values of III-nitride LDs, the 1D drift diffusion model simulation was performed using SiLENSe 5.4 software [14]. 2D optical waveguide calculations were performed by CAMFR module [15]. Based on the refractive index profile, the optical mode distribution was calculated and used to estimate confinement factors. A simple linear model correlating $\mathrm{Mg}$ concentration with light absorption was assumed. Based on our previous experimental study, a relation $\alpha_{\mathrm{Mg}}=112 \mathrm{~cm}^{2} \times \mathrm{Mg}$ concentration (in units of $10^{19} \mathrm{~cm}^{-3}$ ) was determined [16].

The considered structure is shown in Fig. 1 and consists of $700 \mathrm{~nm} \mathrm{Al}_{0.07} \mathrm{Ga}_{0.93} \mathrm{~N}: \mathrm{Si}$ bottom cladding and $100 \mathrm{~nm} \mathrm{GaN}: \mathrm{Si}$ - both layers have a silicon doping level of

\begin{tabular}{|c|c|c|c|}
\hline \multirow{3}{*}{$\mathrm{SiO}_{2}$} & & $100 \mathrm{~nm} \mathrm{Au}$ & \multirow{3}{*}{$\mathrm{SiO}_{2}$} \\
\hline & \multicolumn{2}{|r|}{$65 \mathrm{~nm} \ln _{0.02} \mathrm{Ga}_{0.98} \mathrm{~N}: \mathrm{Mg}$} & \\
\hline & VI & $600 \mathrm{~nm} \mathrm{Al} \mathrm{O}_{0.02} \mathrm{Ga}_{0.98} \mathrm{~N}: \mathrm{Mg}$ & \\
\hline & V & 100 nm GaN:Mg & \\
\hline & III & $20 \mathrm{~nm} \mathrm{Al}_{0.13} \mathrm{Ga}_{0.87} \mathrm{~N}: \mathrm{Mg}$ & \\
\hline & II & $110 \mathrm{~nm} \mathrm{In}_{0.04} \mathrm{Ga}_{0.96} \mathrm{~N}$ & \\
\hline & I & $25 \mathrm{~nm} \ln _{0.17} \mathrm{Ga}_{0.83} \mathrm{~N}$ & \\
\hline & II & $110 \mathrm{~nm} \mathrm{In}_{0.04} \mathrm{Ga}_{0.96} \mathrm{~N}$ & \\
\hline & IV & $100 \mathrm{~nm} \mathrm{GaN}: \mathrm{Si}$ & \\
\hline & VII & $700 \mathrm{~nm} \mathrm{Al}{ }_{0.07} \mathrm{Ga}_{0.93} \mathrm{~N}: \mathrm{Si}$ & \\
\hline & & $50 \mathrm{~nm}$ GaN:Si & \\
\hline & & $100 \mu \mathrm{m}$ GaN substrate & \\
\hline & & $100 \mathrm{~nm} \mathrm{Au}$ & \\
\hline
\end{tabular}

Fig. 1. Schematic of the simulated structure. 


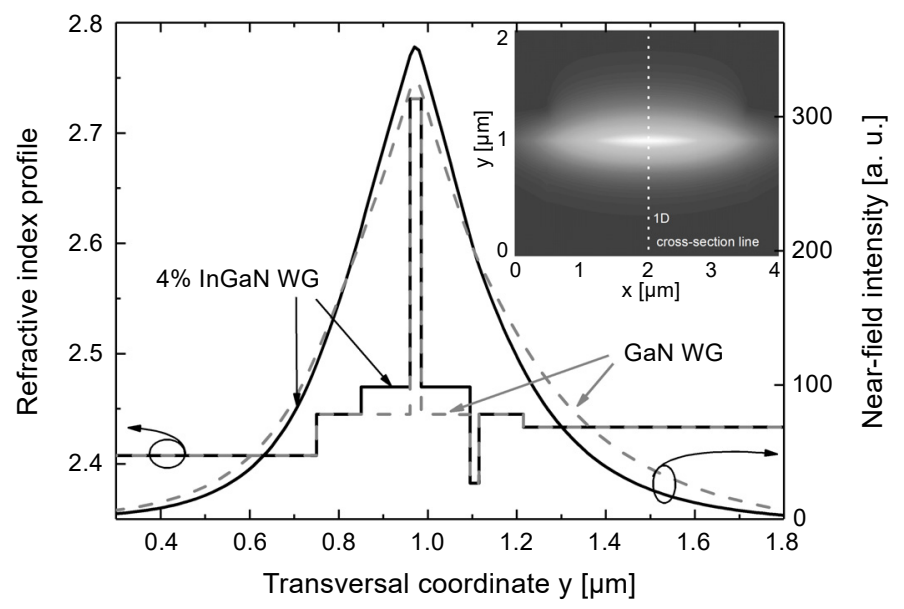

Fig. 2. Calculated 1D optical field distribution for $\mathrm{LD}$ with $\mathrm{In}_{0.04} \mathrm{Ga}_{0.96} \mathrm{~N}$ waveguide (solid line) and GaN waveguide (dashed line); insert presents 2D map of optical field for $\mathrm{LD}$ with $\operatorname{In}_{0.04} \mathrm{Ga}_{0.96} \mathrm{~N}$ waveguide.

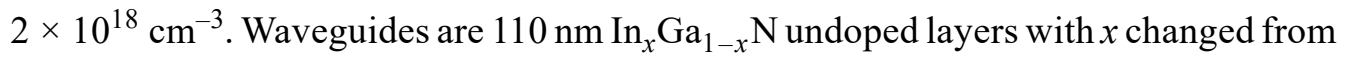
0 to $12 \%$. On the top of the upper waveguide there is a $20 \mathrm{~nm}$ p-type $\mathrm{Al}_{0.13} \mathrm{Ga}_{0.87} \mathrm{~N}$ EBL . The $\mathrm{Mg}$ doping concentration is changed in EBL in the range from $2 \times 10^{18} \mathrm{~cm}^{-3}$ to $6.5 \times 10^{19} \mathrm{~cm}^{-3}$. Next the p-type region with the doping level of $1 \times 10^{18} \mathrm{~cm}^{-3}$ consisting of $100 \mathrm{~nm} \mathrm{GaN}$ and $600 \mathrm{~nm} \mathrm{Al}_{0.02} \mathrm{Ga}_{0.98} \mathrm{~N}$ upper cladding is placed. This is capped with $65 \mathrm{~nm} \mathrm{In}_{0.02} \mathrm{Ga}_{0.98} \mathrm{~N}$ contact layer. The active region of LD consists of a single $25 \mathrm{~nm}$ thick $\operatorname{In}_{0.17} \mathrm{Ga}_{0.83} \mathrm{~N}$ quantum well $[\underline{17}, \underline{18}]$. An exemplary cross-section of the optical mode is presented in Fig. 2. In calculation, the $3 \mu \mathrm{m}$ wide and $670 \mathrm{~nm}$ high mesa covered with $\mathrm{SiO}_{2}$ on both sides is considered. Gold contacts are on the top of the mesa and on the bottom of the substrate.

\section{Results and discussion}

\subsection{Influence of InGaN waveguide on mode overlap with Mg-doped layers}

As was previously shown, replacing the GaN with InGaN waveguide in III-nitride LD increases the confinement of the optical mode with the active region, because of higher refractive index of InGaN $[\underline{7}, \underline{9}]$. The increase of mode confinement with the active region also changes the confinement factors $\Gamma$ in other layers, so the overall contribution of these layers to total $\alpha_{\mathrm{i}}$ will change. This is extremely important for designing LD structure with low optical losses. The changes in confinement factors of quantum well (QW), WGs, EBL, and layers adjacent to the QW as a function of indium composition in WGs are shown in Fig. 3.

The obvious consequence of increasing indium content in waveguides is an increase of $\Gamma$ with the active region (black solid line in Fig. 3), which should have a positive influence on device performance by decreasing threshold current density $j_{\text {th }}$. However, one has to remember that all confinement factors are influenced. The most important 


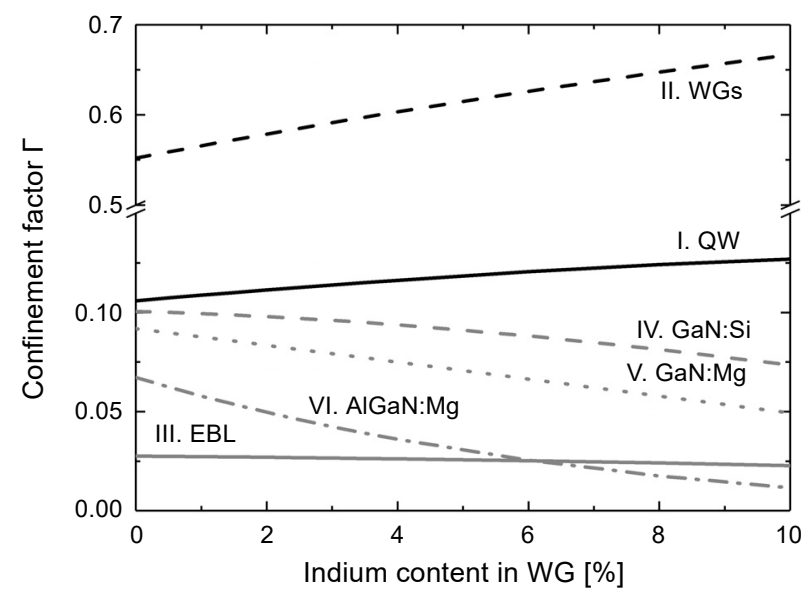

Fig. 3. Dependence of confinement factors of different layers on In content in waveguide.

are the waveguide itself and Mg-doped layers. The $\Gamma$ of waveguide is equal to 0.552 and 0.667 for $x=0.00$ and $x=0.10$, respectively. Such a high overlap of the optical mode with WG can cause severe increase of $\alpha_{\mathrm{i}}$ if absorption coefficient $\alpha_{\text {InGaN }}$ increases with In content. In principle, the Urbach tail in high In content In GaN might cause some absorption losses. However, at this point, there is still an open question due to the lack of experimental data. In the future it is necessary to perform separate experiments to estimate the influence of InGaN WG on $\alpha_{i}$.

We found that, in the studied range of In content of InGaN WG (from GaN WG to $10 \% \mathrm{InGaN} \mathrm{WG}$ ), the confinement factors of $\mathrm{AlGaN}$ and $\mathrm{GaN}$ p-type layers decreases from 0.067 to 0.012 and from 0.092 to 0.049 , respectively. On the other hand, $\Gamma_{\mathrm{EBL}}$ (grey solid line) remains almost unchanged. It is worth noticing that $\Gamma_{\mathrm{EBL}}$ for high In content is almost half of $\Gamma_{\mathrm{GaN}: \mathrm{Mg}}$ and even larger than $\Gamma_{\mathrm{AlGaN}: \mathrm{Mg}}$. Usually EBL doping is an order of magnitude higher than other p-type layers. These two effects can lead to the domination of EBL over other p-type layers in terms of contribution to the total $\alpha_{i}$, specially for high In content in waveguides.

\subsection{Influence of InGaN waveguide on injection efficiency}

We will determine now, the influence of In content in WG on electrical and carrier transport properties. Drift diffusion simulation was used to calculate the $\eta_{\mathrm{i}}$ and the results are shown in Fig. 4a. It is important to stress that the $\eta_{\mathrm{i}}$ depends on current density. For low current densities $j<200 \mathrm{~A} / \mathrm{cm}^{2}$, the $\eta_{\mathrm{i}}$ is close to unity up to the $8 \% \mathrm{In}$ in the waveguide composition. However, for higher current densities a decrease of $\eta_{\mathrm{i}}$ is observed. This drop is more significant for low In content in the waveguide. For In content higher than $8 \%$, the $\eta_{\mathrm{i}}$ is lower than unity even at low current densities. This leads to the existence of optimum value of In content in WG somewhere around 8\%. For a typical operating current densities $j=3.5 \mathrm{kA} / \mathrm{cm}^{2}$, injection the efficiency equals 0.65 , 


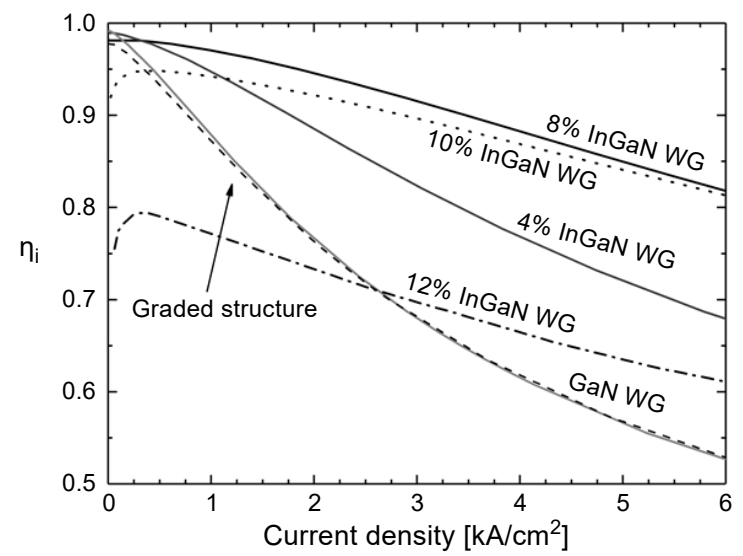

a

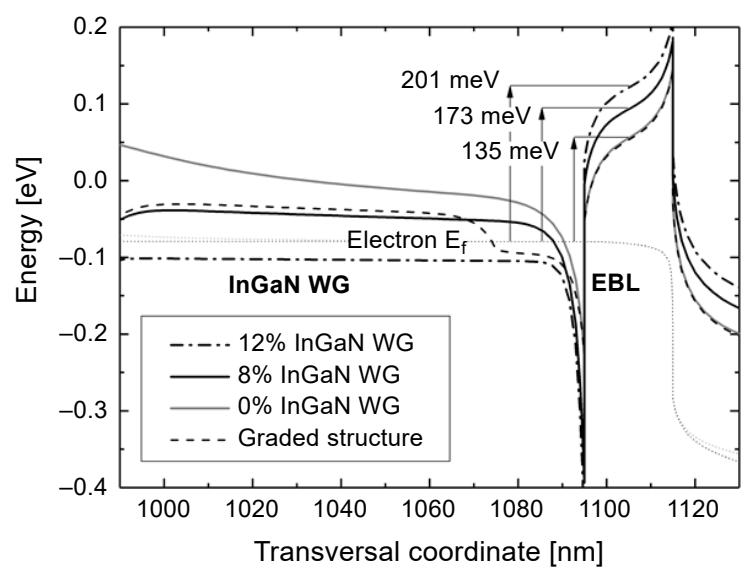

b

Fig. 4. Dependence of injection efficiency $\eta_{\mathrm{i}}$ calculated with drift diffusion model on current density (a). Part of conduction band profile for GaN, 8\%, 12\% and graded InGaN waveguide. Graded structure consists of $90 \mathrm{~nm} 8 \% \mathrm{InGaN}$ and $20 \mathrm{~nm}$ pre-EBL grading regime from $8 \% \mathrm{InGaN}$ to GaN. EBL doping level is constant $\mathrm{Mg}: 2 \times 10^{19} \mathrm{~cm}^{-3}(\mathbf{b})$.

0.90 and 0.68 for $\mathrm{GaN}, 8 \%$ and $12 \%$ InGaN waveguides, respectively. Therefore, for constant doping level of EBL, the InGaN WGs, up to $8 \%$ In content, provide better carrier injection to active region. From this point of view, the use of InGaN WGs is beneficial for realizing efficient LD devices.

To explain the origin of the difference in $\eta_{\mathrm{i}}$ invoked by InGaN WG, the band diagrams are shown in Fig. $4 \mathbf{b}$. The conduction bands were calculated for $j=3.5 \mathrm{kA} / \mathrm{cm}^{2}$. The energy barrier created by EBL is equal to 135, 173, and $201 \mathrm{meV}$ for GaN, $8 \%$ and $12 \%$ InGaN WG, respectively. The increase of EBL barrier height is responsible for an initial increase of $\eta_{\mathrm{i}}$. However, for In content higher than $8 \%, \eta_{\mathrm{i}}$ starts to drop as can be seen in Fig. 4a. This is a result of additional carrier accumulation in the WG regime, which causes unwanted recombination. Interestingly, the whole positive im- 
pact of InGaN WG on $\eta_{\mathrm{i}}$ arises only due to the difference in bandgaps at the WG and EBL interface. To show it, we have performed calculations on structure consisting of $8 \%$ InGaN WG but the composition is graded from $8 \%$ to $0 \%$ on the last $20 \mathrm{~nm}$. The resulting structure has an interface between WG and EBL consisting of GaN and AlGaN. Grading WG exhibits a similar $\Gamma$ as $8 \% \operatorname{InGaN}$ but $\eta_{\mathrm{i}}$ values are exactly the same as in the case of GaN WG. Therefore realization of the interface between AlGaN and $\mathrm{InGaN}$ is crucial for ensuring high $\eta_{\mathrm{i}}$. Similar effect of an increased carrier injection was observed if an InGaN layer is introduced between GaN WG and AlGaN EBL [19]. Then, an InGaN-AlGaN interface is formed.

As was mentioned previously, one of the drawbacks of using InGaN waveguides, despite technological issues in growing high indium content thick layers [20 20, 21], is higher carrier accumulation [19, 22]. MeHARI et al. [22] found that in semipolar InGaN LDs, when a part of $\mathrm{GaN}$ waveguide is replaced by InGaN layer, carriers accumulate in WG. The carrier concentration in the order of $10^{19} \mathrm{~cm}^{-3}$ was found to decrease $\eta_{\mathrm{i}}$ due to unwanted recombination of carriers. This problem can be solved by starting WG layer with InGaN without the unintentionally doped GaN layer. In Fig. 5 the band profiles and carrier concentrations of previously described $8 \%$ InGaN WG structure and structure with $20 \mathrm{~nm} \mathrm{GaN}$ layer placed between QW and InGaN WG are shown. When GaN layer is present, the carrier concentration in InGaN WG equals $6 \times 10^{18} \mathrm{~cm}^{-3}$. By using fully InGaN waveguide, the carriers do not accumulate and concentration drops by an order of magnitude. The relative EBL barrier height is the same in these two structures.

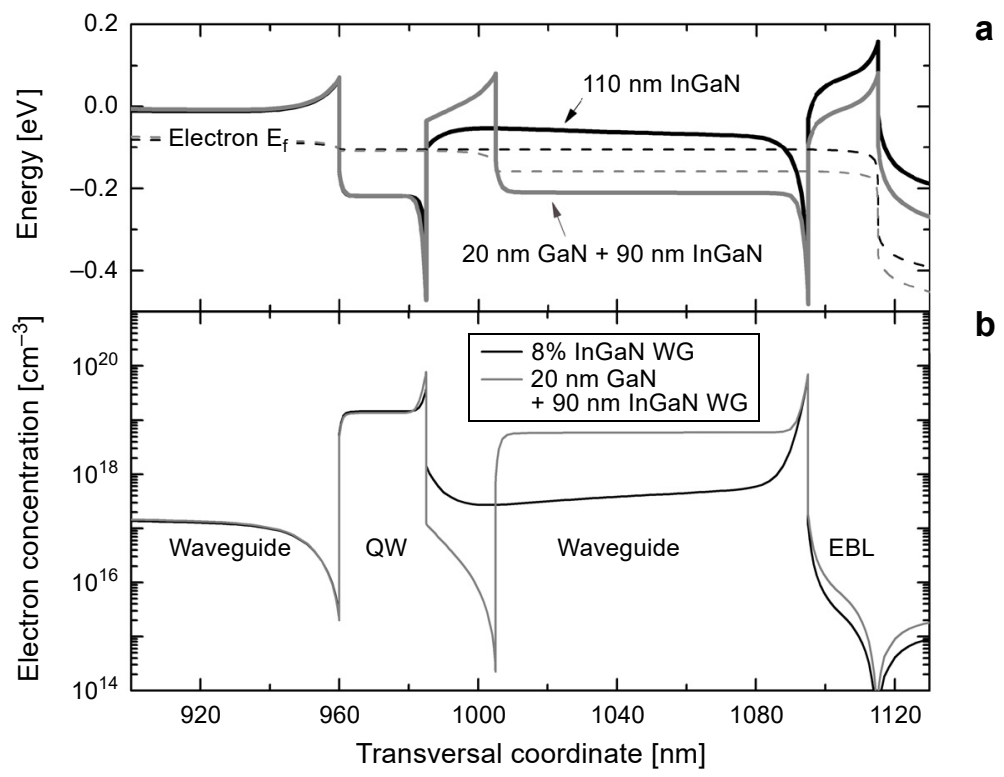

Fig. 5. Conduction band profile (a) and electron concentration (b) in waveguide layers for structures with full 8\% InGaN (black line) and with GaN layer between QW and WG (grey line) for $j=3.5 \mathrm{kA} / \mathrm{cm}^{2}$ based on drift diffusion simulations. 

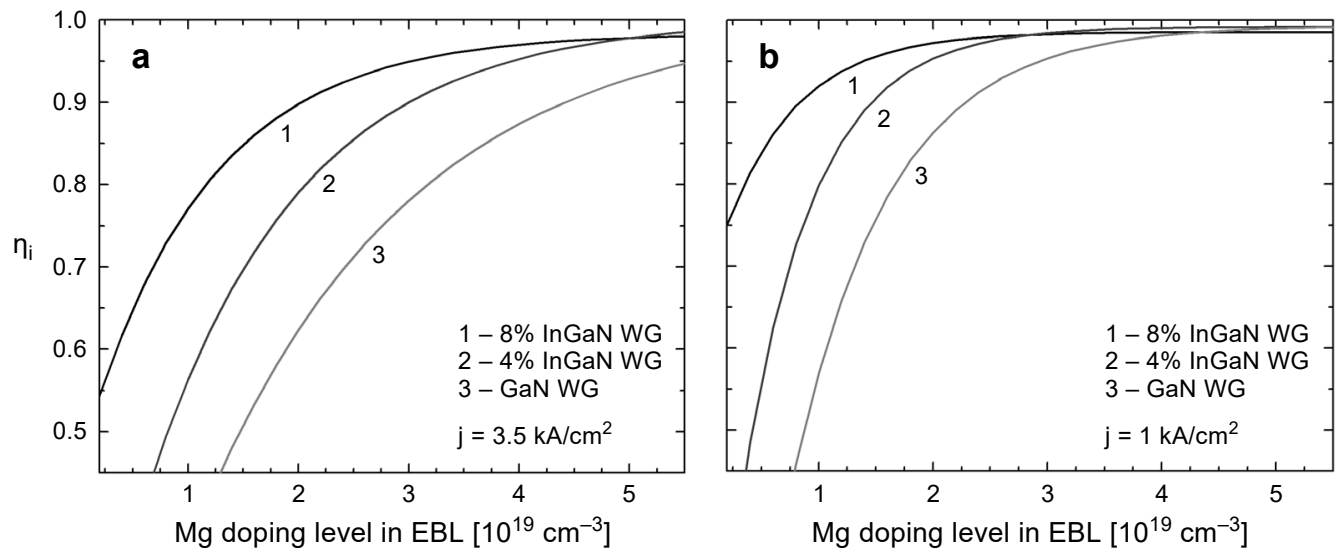

Fig. 6. Calculated injection efficiency as a function of EBL doping level for different InGaN waveguide compositions for current density $3.5 \mathrm{kA} / \mathrm{cm}^{2}(\mathbf{a})$, and $1 \mathrm{kA} / \mathrm{cm}^{2}(\mathbf{b})$.

Because of the influence of WG composition on the EBL height, the doping level of EBL has to be also discussed since doping itself strongly affects the barrier height [16]. As was discussed in Section 3.1, the EBL contribution to $\alpha_{\mathrm{i}}$ for high In content WGs increases, so desirably the $\mathrm{Mg}$ level should be kept as low as possible. Figures $6 \mathbf{a}$ and $6 \mathbf{b}$ present the calculated dependence of $\eta_{\mathrm{i}}$ on $\mathrm{Mg}$ doping for current densities of 3.5 and $1 \mathrm{kA} / \mathrm{cm}^{2}$, respectively. For $j=3.5 \mathrm{kA} / \mathrm{cm}^{2}$ and high $\mathrm{Mg}$ doping $\left(\mathrm{Mg}>4 \times 10^{19} \mathrm{~cm}^{-3}\right)$, the $\eta_{\mathrm{i}}$ is close to unity. For $\mathrm{Mg}$ doping $\mathrm{Mg}=2 \times 10^{19} \mathrm{~cm}^{-3}$, the $\eta_{\mathrm{i}}$ is still close to unity only for $8 \%$ InGaN WG. Therefore for lower InGaN compositions the $\eta_{i}$ drops. As a result, one can achieve equal $\eta_{\mathrm{i}}$ for GaN WG and $4.3 \times 10^{19} \mathrm{~cm}^{-3} \mathrm{Mg}$ concentration and $8 \%$ InGaN and $2 \times 10^{19} \mathrm{~cm}^{-3} \mathrm{Mg}$. To keep the $\eta_{\mathrm{i}}$ on acceptable level and take advantage of the decreased $\alpha_{i}$, the high In content WGs has to be used. The $\eta_{i}$ decrease rate is noticeably lower for high In, thus the $\mathrm{Mg}$ content can be more reduced in these structures. Even higher enhancement can be achieved if threshold current density could be lowered to $1 \mathrm{kA} / \mathrm{cm}^{2}$. As can be seen in Fig. $6 \mathbf{b}$, high $\eta_{\mathrm{i}}$ can be achieved even for $\mathrm{Mg}$ doping as low as $1 \times 10^{19} \mathrm{~cm}^{-3}$. Importantly, decrease of $j_{\text {th }}$ can be obtained by decreasing the $\mathrm{Mg}$ doping level. A lower $\mathrm{Mg}$ level can therefore help in achieving lower $j_{\text {th }}$ if the $\eta_{\mathrm{i}}$ is kept at high values.

\subsection{Modelling the operating parameters of LDs}

For describing the influence of InGaN waveguides on the operation of real LD, the parameters such as threshold current density $j_{\text {th }}$ and slope efficiency SE will be discussed. Both of them are related to $\eta_{i}$ and $\alpha_{i}$ through [리]:

$$
j_{\text {th }}=\frac{\alpha_{\mathrm{i}}+\alpha_{\mathrm{m}}}{\eta_{\mathrm{i}} \Gamma_{\text {active }} \frac{\mathrm{d} g}{\mathrm{~d} j}}+j_{\text {trans }}
$$




$$
\mathrm{SE}=\eta_{\mathrm{i}} \frac{\alpha_{\mathrm{m}}}{\alpha_{\mathrm{i}}+\alpha_{\mathrm{m}}} \frac{h v}{q}
$$

where $g$ is the material gain, $\Gamma_{\text {active }}$ is the confinement factor of active region, $j_{\text {trans }}$ is the transparency current, $\alpha_{\mathrm{m}}$ are mirror losses, $v$ is the frequency of emitted light, $q$ is the elementary charge, and $h$ is the Planck constant; $\alpha_{\mathrm{i}}$ is the sum of losses originating from highly doped EBL $\alpha_{\mathrm{EBL}}$ and additional losses from other layers $\alpha_{0}$. The Mg doped layers absorption coefficient $\alpha_{\mathrm{Mg}}$ is assumed to increase linearly with $\mathrm{Mg}$ doping through the relation $\alpha_{\mathrm{Mg}}=112 \mathrm{~cm}^{2} \times \mathrm{Mg}$ concentration (in units of $10^{19} \mathrm{~cm}^{-3}$ ), which was found in our previous paper [16]. The $\alpha_{\mathrm{EBL}}$ for $\mathrm{Mg}: 2 \times 10^{19} \mathrm{~cm}^{-3}$ equals 5.4, 5.9, and $6.2 \mathrm{~cm}^{-1}$, for $8 \%, 4 \%$ and $0 \%$ InGaN WG, respectively. Internal losses that originate from all other layers expect to be EBL are assumed to be a product of absorption coefficients and calculated confinement factors. Due to the low doping in other layers, the $\alpha_{0}$ is independent of WG composition and is equal to $\alpha_{0}=(9.5 \pm 0.05) \mathrm{cm}^{-1}$. The model lacks a dependence of absorption in InGaN WG on In composition.

Taking into consideration that $\eta_{\mathrm{i}}$ and $\Gamma$ change with In content in WG, the theoretical $j_{\text {th }}$ and SE values were calculated and presented in Figs. 7a and 7b. There is an interplay of $\eta_{\mathrm{i}}$ and $\alpha_{\mathrm{Mg}}$ which causes a complicated dependence of $j_{\text {th }}$ and SE on $\mathrm{Mg}$ doping level in EBL. In the low doping regime, the $j_{\text {th }}$ is high and SE is low due to electron overflow and thus low $\eta_{\mathrm{i}}$. As the doping level is increased, $j_{\text {th }}$ and SE both improve up to a point, in which the increase in $\eta_{\mathrm{i}}$ is insignificant. Then an increase in $j_{\text {th }}$ and decrease of SE can be observed due to increasing $\alpha_{\mathrm{Mg}}$.

General enhancement of LD operating parameters for high In composition is observed due to the increased $\Gamma$ and $\eta_{\mathrm{i}}$. The $\eta_{\mathrm{i}}$ decrease rate is slower for higher In contents thus the shift of the optimum Mg doping level towards lower doping concentration is observed. From this analysis the optimum doping points for different In compositions are extracted and presented in Fig. 8 with black circles. Consequently, optimum device
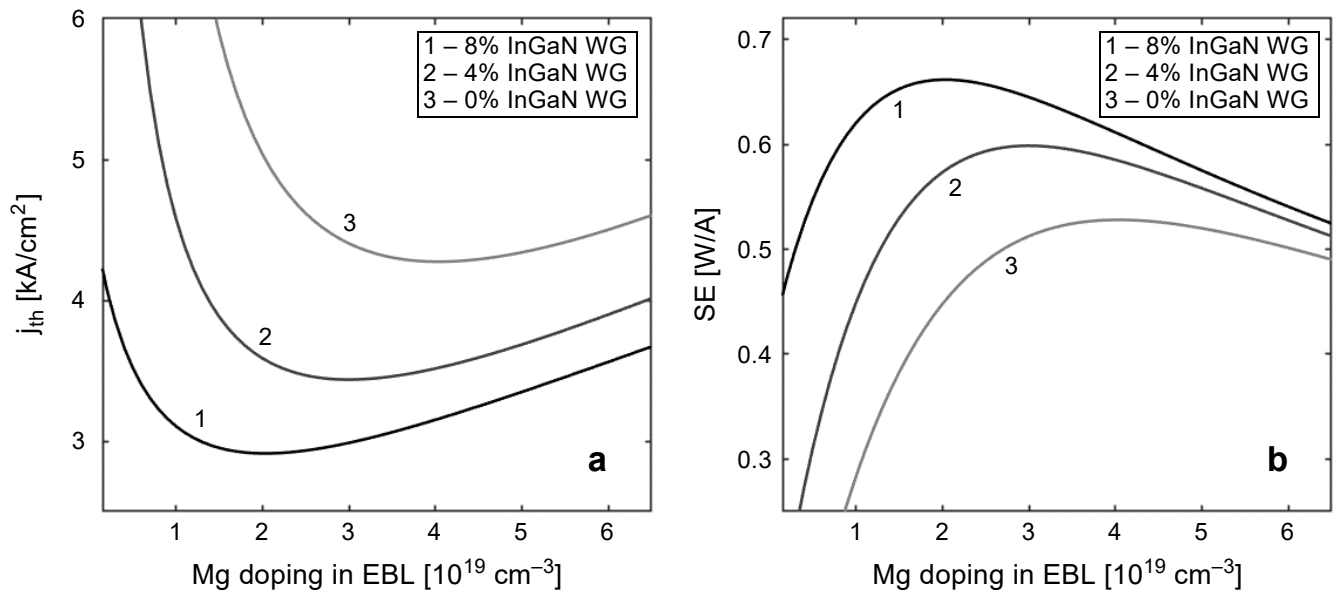

Fig. 7. Dependence of threshold current density (a) and slope efficiency (b) on EBL Mg doping level. $\mathrm{LD}$ operation wavelength is $450 \mathrm{~nm}$. Resonator length is $1000 \mu \mathrm{m}$. Cleaved uncoated mirrors are assumed. 


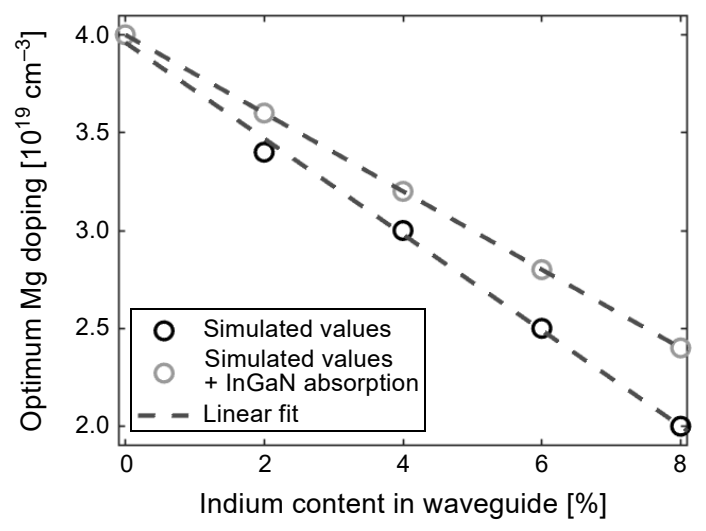

Fig. 8. Dependence of optimum EBL doping concentrations on In composition. The dependence for artificial absorption dependence on In content is also showed.

operation with GaN WGs requires higher Mg doping and therefore high optical losses are present. The high In structures have lower $j_{\text {th }}$ which stands in agreement with previous experimental reports []ㅡ. For devices with lower $j_{\text {th }}$, the observed difference between different WG designs is expected to be smaller since $\eta_{\mathrm{i}}$ decrease rate is smaller as can be seen in Fig. $6 \mathbf{b}$. However, in devices with high In content WG, an additional source of optical losses may appear. To test the influence of absorption by InGaN WG on optimum Mg doping of EBL, we have assumed a linear increase of absorption coefficient with In content. In this model the absorption coefficient linearly increases with In content in such a way that $4 \% \mathrm{InGaN}$ absorption coefficient increases by $10 \mathrm{~cm}^{-1}$ and $8 \%$ InGaN by $20 \mathrm{~cm}^{-1}$. This is in our opinion an upper limit for undoped layer. The results are shown in Fig. 8 with grey circles. The linear decrease of optimum $\mathrm{Mg}$ doping in EBL on InGaN WGs composition is observed in both cases.

\section{Conclusions}

The influence of different compositions of InGaN waveguide on injection efficiency in III-nitride LDs was discussed. It is found that the increase of In composition in waveguides effectively increases the barrier of EBL and prevents the electron overshot. We found that the application of InGaN waveguide can allow to reduce the Mg doping level in EBL and thus reduce the optical losses originating from this layer. The important role of InGaN-AlGaN interface in keeping high $\eta_{\mathrm{i}}$ was discussed. The high In content in InGaN WGs ensures also higher mode confinement in the active region and lower in layers causing high optical losses. Presented aspects lead to the increased performance of LD with InGaN WGs in comparison to the GaN ones.

Acknowledgements - This work has been partially supported by TEAMTECH POIR.04.04.00-00-210C/ 16-00 project of the Foundation for Polish Science co-financed by the European Union under the European Regional Development Fund and the National Centre for Research and Development grants LIDER/29/ 0185/L-7/15/NCBR/2016 and LIDER/35/0127/L-9/17/NCBR/2018. 


\section{References}

[1] Wierer J.J., Tsao J.Y., Sizov D.S., Comparison between blue lasers and light-emitting diodes for future solid-state lighting, Laser and Photonics Reviews 7(6), 2013 pp. 963-993, DOI: 10.1002/lpor. 201300048.

[2] Kawaguchi M., Imafuji O., Nozaki S., Hagino H., Takigawa S., Katayama T., Tanaka T., Optical -loss suppressed InGaN laser diodes using undoped thick waveguide structure, Proceedings of SPIE 9748, 2016, article 974818, DOI: 10.1117/12.2212011.

[3] Zhang L.Q., Jiang D.S., Zhu J.J., Zhao D.G., Liu Z.S., Zhang S.M., Yang H., Confinement factor and absorption loss of AlInGaN based laser diodes emitting from ultraviolet to green, Journal of Applied Physics 105(2), 2009, article 023104, DOI: 10.1063/1.3068182.

[4] Muziol G., Turski H., Siekacz M., Sawicka M., Wolny P., Perlin P., Skierbiszewski C., Determination of gain in AlGaN cladding free nitride laser diodes, Applied Physics Letters 103(6), 2013, article 061102, DOI: $10.1063 / 1.4817754$.

[5] Lermer T., Schillgalies M., Breidenassel A., Queren D., Eichler C., Avramescu A., Muller J., Scheibenzuber W., Schwarz U., Lutgen S., Strauss U., Waveguide design of green InGaN laser diodes, Physica Status Solidi (A) 207(6), 2010, pp. 1328-1331, DOI: 10.1002/pssa.200983410.

[6] Strauss U., Eichler C., Rumbolz C., Lell A., Lutgen S., Tautz S., Schillgalies M., Brüninghoff S., Beam quality of blue InGaN laser for projection, Physica Status Solidi (C) 5(6), 2008, pp. 2077-2079, DOI: $10.1002 / \mathrm{pssc} .200778417$.

[7] Huang C., Lin Y., Tyagi A., Chakraborty A., Ohta H., Speck J.S., DenBaars S.P., Nakamura S., Optical waveguide simulations for the optimization of InGaN-based green laser diodes, Journal of Applied Physics 107(2), 2010, article 023101, DOI: 10.1063/1.3275325.

[8] Muziol G., Turski H., Siekacz M., Wolny P., Grzanka S., Grzanka E., Perlin P., Skierbiszewski C., Enhancement of optical confinement factor by In GaN waveguide in blue laser diodes grown by plasma-assisted molecular beam epitaxy, Applied Physics Express 8(3), 2015, article 032103, DOI: 10.7567/APEX.8.032103.

[9] Chen P., Feng M.X., Jiang D.S., Zhao D.G. Liu Z.S., Li L., Wu L.L., Le L.C., Zhu J.J., Wang H., ZHANG S.M., YANG H., Improvement of characteristics of InGaN-based laser diodes with undoped InGaN upper waveguide layer, Journal of Applied Physics 112(11), 2012, article 113105, DOI: $10.1063 / 1.4768287$.

[10] Muziol G., Turski H., Siekacz M., Grzanka S., Perlin P., Skierbiszewski C., Elimination of leakage of optical modes to GaN substrate in nitride laser diodes using a thick In GaN waveguide, Applied Physics Express 9(9), 2016, article 092103, DOI: 10.7567/APEX.9.092103.

[11] Kioupakis E., Rinke P., Schleife A., Bechstedt F., Van de Walle C.G., Free-carrier absorption in nitrides from first principles, Physical Review B 81(24), 2010, article 241201(R), DOI: $10.1103 /$ PhysRevB.81.241201.

[12] Uchida S., Takeya M., Ikeda S., Mizuno T., Fujimoto T., Matsumoto O., Goto S., Tojyo T., Ikeda M., Recent progress in high-power blue-violet lasers, IEEE Journal of Selected Topics in Quantum Electronics 9(5), 2003, pp. 1252-1259, DOI: 10.1109/JSTQE.2003.820910.

[13] Kuramoto M., Sasaoka C., Futagawa N., Nido M., Yamaguchi A.A., Reduction of internal loss and threshold current in a laser diode with a ridge by selective re-growth (RiS- $L D)$, Physica Status Solidi (A) 192(2), 2002, pp. 329-334, DOI: 10.1002/1521-396X(200208)192:2\%3C329::AID-PS SA329\%3E3.0.CO;2-A.

[14] SiLENSe 5.4 package, http://str-soft.com/products/SiLENSe/ (accessed October 12, 2019).

[15] CAMFR (CAvity Modelling FRamework), http://camfr.sourceforge.net (accessed October 12, 2019).

[16] Hajdel M., Muziol G., Nowakowski-Szkudlarek K., Siekacz M., Feduniewicz-Żmuda A., Wolny P., SKIERBISZEWSKI C., Influence of electron blocking layer on properties of In GaN-based laser diodes grown by plasma-assisted molecular beam epitaxy, Acta Physica Polonica A 136(4), 2019, pp. 593-597, DOI: 10.12693/APhysPolA.136.593. 
[17] Muziol G., Hajdel M., Siekacz M, Szkudlarek K, Stanczyk S., Turski H., Skierbiszewski C., Optical properties of III-nitride laser diodes with wide InGaN quantum wells, Applied Physics Express 12(7), 2019, article 072003, DOI: 10.7567/1882-0786/ab250e.

[18] Muziol G., Turski H., Siekacz M., Szkudlarek K., Janicki L., Baranowski M., Zolud S., Kudrawiec R., Suski T., SKierbiszewski C., Beyond quantum efficiency limitations originating from the piezoelectric polarization in light-emitting devices, ACS Photonics 6(8), 2019, pp. 1963-1971, DOI: 10.1021 /acsphotonics.9b00327.

[19] Le L.C., Zhao D.G., Jiang D.S., Chen P., Liu Z.S., Yang J., He X.G., Li X.J., Liu J.P., Zhu J.J., Zhang S.M., YANG H., Suppression of electron leakage by inserting a thin undoped InGaN layer prior to electron blocking layer in InGaN-based blue-violet laser diodes, Optics Express 22(10), 2014, pp. 11392-11398, DOI: 10.1364/OE.22.011392.

[20] Holec D., Costa P.M.F.J., Kappers M.J., Humphreys C.J., Critical thickness calculations for InGaN/ GaN, Journal of Crystal Growth 303(1), 2007, pp. 314-317, DOI: 10.1016/j.jcrysgro.2006.12.054.

[21] Leyer M., Stellmach J., Meissner Ch., Pristovsek M., Kneissl M., The critical thickness of InGaN on (0 00 1) GaN, Journal of Crystal Growth 310(23), 2008, pp. 4913-4915, DOI: 10.1016/j.jcrysgro. 2008.08.021.

[22] Mehari S., Cohen D.A., Becerra D.L., Nakamura S., DenBaars S.P., Semipolar InGaN blue laser diodes with a low optical loss and a high material gain obtained by suppression of carrier accumulation in the p-waveguide region, Japanese Journal of Applied Physics 58(2), 2019, article 020902, DOI: $10.7567 / 1347-4065 / a a f 4 b 4$.

[23] Coldren L.A., Corzine S.W., Mašanović M.L., Diode Lasers and Photonic Integrated Circuits, Second Edition, Wiley, 2012, pp. 45-246, DOI: 10.1002/9781118148167.

Received October 16, 2019 in revised form January 8, 2020 